\title{
CONTRIBUIÇÕES DA ERA MAO TSÉ-TUNG PARA A INDUSTRIALIZAÇÃO CHINESA*
}

\author{
Luís Felipe Lopes Milaréa \\ Antônio Carlos Diegues ${ }^{b}$
}

RESUMO: Este artigo busca resgatar algumas reformas realizadas por Mao Tsé-Tung (1949-1976) para o processo de industrialização chinesa. Usualmente quando se analisa este processo de industrialização parte-se da Reorientação da Estratégia de Desenvolvimento de Deng Xiaoping a partir de 1978; no entanto, será argumentado que o legado deixado por Mao Tsé-Tung foi fundamental para garantir a acelerada modernização industrial vivenciada no período seguinte.

PALAVRAS-CHAVE: Industrialização; política industrial.

CLASSIFICAÇÃO JEL: O14; O25.

\footnotetext{
* Artigo recebido em 15/05/2012 e aprovado em 08/08/2012.

${ }^{a}$ Mestre em Economia pela Universidade Federal de São Carlos (UFSCar). Contato: luismilare@gmail.com. ${ }^{\mathrm{b}}$ Doutor em Economia pela Universidade Estadual de Campinas (UNICAMP) e professor do Departamento de Economia da UFSCar. Contato: acdiegues@yahoo.com.br.
} 


\title{
CONTRIBUTIONS OF MAO ZEDONG ERA FOR CHINESE INDUSTRIALIZATION
}

\begin{abstract}
The main purpose of this paper is to present some of Mao Zedong's contributions to the industrialization process of China. Usually China's industrial transformation is analized taking the year 1978 and Deng Xiaoping as a starting point; however, we argue that the economic reforms introduced by Mao Zedong helped underpin the success obtained by Deng Xiaoping's industrial transformation after 1978.
\end{abstract}

KEYWORDS: Industrialization; industrial policy. 


\section{INTRODUÇÃO}

O desfecho de uma estratégia de industrialização depende, em grande medida, das condições econômicas iniciais encontradas pelos governantes que as colocam em prática. Usualmente, para analisar o processo de industrialização chinesa, parte-se da Reorientação da Estratégia de Desenvolvimento (RED) introduzida por Deng Xiaoping, em 1978. Este artigo busca contribuir com o debate acerca do processo de industrialização chinesa resgatando algumas contribuições do período anterior a Deng Xiaoping que colaboraram para a acelerada transformação industrial vivenciada pelo país a partir de então.

Ao analisar a industrialização chinesa a maior parte dos autores cita uma ou outra reforma empreendida por Mao Tsé-Tung como determinante para o sucesso da Reorientação da Estratégia de Desenvolvimento. No entanto, raramente há espaço para o detalhamento de tais reformas. Quando há espaço para uma discussão mais aprofundada do período, usualmente, foca-se o debate nas implicações do "Grande Salto Adiante", da Revolução Cultural ou a criação das Township and Village Enterprises (TVEs), dado que estes foram os grandes acontecimentos do período (1949-1976). No entanto, as contribuições não se esgotam nestes grandes episódios. Desse modo, defende-se a tese neste artigo de que inúmeros outros encadeamentos colaboraram para o bom desempenho da economia chinesa no pós-78.

Dessa forma, buscar-se-á neste artigo resgatar algumas reformas - já citadas por outros autores, porém, pouco exploradas - realizadas por Mao Tsé-Tung (1949-1976), que alicerçaram o sucesso da estratégia de industrialização do período subsequente (1978-2011), colhendo dados secundários e buscando suas evidências. Assim, quatro reformas merecerão especial atenção: a quebra do imobilismo tradicional, a formação da indústria pesada, o aumento da área irrigada e a criação de uma indústria de insumos agrícolas.

\section{A QUEBRA DO IMOBILISMO TRADICIONAL}

Durante o império a crença era de que a China continuava a ser a potência que fora em séculos anteriores. O rápido desenvolvimento científico e tecnológico auferido pelos países que obtiveram êxito em realizar suas revoluções industriais era ignorado, bem como as diversas derrotas militares ocorridas no passado próximo. A sociedade chinesa, milenar, mantinha o entendimento de que sua cultura era superior e que seu "modelo" não poderia estar errado. Esta paralisia tinha origem, em grande medida, nos valores do confucionismo e significava, em última instância, o reconhecimento das decisões do imperador como emanadas de Deus. Como mostra Leão: 
(...) a figura do imperador, que representava a harmonia existente entre o céu e terra, congelava o poder político e econômico da sociedade chinesa. Esses líderes eram os representantes de um Deus cósmico, as figuras escolhidas para governar a sociedade, eram os sacerdotes legítimos da China. Logo, o povo chinês devia reconhecê-los como tais, respeitando-os e acatando suas decisões, pois somente assim a harmonia da civilização seria alcançada. Isso obviamente resultou numa estabilização e cristalização das relações sociais. (Leão, 2010, p. 18-19, grifos nossos)

Além da cristalização das relações sociais, existia uma grande fragmentação do povo chinês, dividido em clãs. Um dos fatores explicativos dessa fragmentação é o fato de não existir um elemento religioso que unificasse os cidadãos, além de haver uma rígida separação entre as classes sociais. Era possível observar que as famílias que migravam para as cidades mantinham-se social e economicamente afastadas umas das outras, tendo vínculo exclusivamente com seu clã de origem. Dessa forma, as cidades constituíam-se basicamente como simples distritos administrativos, sem que constituíssem uma rede de integração política e econômica, capaz de enfrentar o poder central (Leão, 2010, p. 20).

Essa paralisia trouxe consigo um caráter deletério ao desenvolvimento de uma sociedade industrial. Era demasiadamente custoso romper com o status quo e avançar rumo à modernização em uma sociedade pautada em valores tão arraigados. Por esse motivo, a quebra do imobilismo tradicional - político e social - era condição necessária para a industrialização e construção de uma sociedade igualitária.

A ruptura com o passado deve ser analisada como um objetivo perseguido por Mao Tsé-Tung durante todo o seu governo. Para Mao, o ímpeto revolucionário deveria ser permanente, ou seja, uma revolução deveria suceder a outra com objetivo último de construir uma sociedade verdadeiramente desenvolvida e igualitária (Nabuco, 2009, p. 4).

Por meio dos processos revolucionários o Estado chinês criava as bases para a centralização do poder nas mãos do partido comunista e, consequentemente, os meios para levar adiante uma estratégia de industrialização com forte controle estatal ${ }^{1}$. Com esses processos quebravam-se o imobilismo e a paralisia. O ímpeto revolucionário de Mao Tsé-Tung buscava inviabilizar a consolidação de uma classe no poder, evitando que esta se beneficiasse do status quo - ganhos advindos da propriedade, do comércio

\footnotetext{
${ }^{1}$ Em entrevista ao jornal da Universidade Estadual de Campinas (2011), o embaixador Amaury Porto de Oliveira ilustra a importância da centralização do poder no PCC para o ímpeto revolucionário chinês: "A China que está assombrando o mundo é um país em revolução permanente. O Partido Comunista está sólido no poder, com quase 80 milhões de membros. Não é um partido do tipo que conhecemos no ocidente, é um movimento social - em todos os escaninhos da vida chinesa o partido está presente, com uma linha própria de construção da sociedade. Ele não é monolítico, havendo várias correntes e um grande debate dentro dele, mas o resultado desta confrontação é a linha central assumida no alto pelo birô político, que representa um consenso de tudo o que está embaixo".
} 
externo, etc. - e paralisasse o processo de transformação necessário à criação de uma sociedade igualitária. Assim, podemos citar três momentos revolucionários em que esses objetivos estavam presentes, quais sejam: na revolução de 1949; no "Grande Salto Adiante" (1958-1960); e, finalmente, na "revolução cultural"2 (1966-1969).

Especial atenção será dada à revolução de 1949, pois esta foi o passo inicial para a tomada do poder com grande dificuldade em se organizar, aglutinar os interesses e viabilizar uma grande transformação com ampla legitimidade. Assim, como mostra Oliveira (2005), pode-se dizer que a revolução comunista de 1949 foi decisiva para que ocorresse uma primeira ruptura desta paralisia:

E os impactos da Revolução de 1949 são também fundamentais para explicar a trajetória futura da China. A revolução varre do solo chinês as forças responsáveis pelo atraso, paralisia e pelas tendências desagregadores do país. São eliminados os restos das antigas burocracias civis e militares que sobreviveram à queda do império, os proprietários de terras parasitários que viviam de rendas e as camadas burguesas ligadas ao comércio exterior, criadas com a ocupação de regiões do país por potências estrangeiras. (Oliveira, 2005, p. 4, grifos nossos)

A revolução e a proclamação da República Popular da China (RPC) se deram com grande legitimidade. Um dos principais determinantes dessa revolução foi o entendimento das diversas esferas da sociedade - camponeses, operários e letrados - da necessidade de uma ampla reforma agrária, em última instância, visando mudanças estruturais em busca da redução das desigualdades sociais existentes. O apoio popular garantiu a união do cidadão chinês em torno desse objetivo, que passou a possuir um vínculo social com os demais cidadãos. Este ponto é especificamente importante, pois a busca de um objetivo comum entre eles - a reforma agrária - foi o que garantiu legitimidade à revolução de 1949. Esta forneceu também as bases para se controlar e coordenar a sociedade - e, consequentemente, a economia - rumo à industrialização pesada.

A tomada de poder por Mao Tsé-Tung em 1949 ocorreu em meio a um caos social: o país estava devastado pela guerra contra o domínio japonês e também pela guerra civil que enfrentara contra os nacionalistas. O cenário econômico estava longe de estável: a agricultura havia sido assolada e a indústria (rudimentar) existente, destruída (Yang, 1990, p. 233-234). É nesse contexto que emerge o consenso acerca da necessidade de uma reforma agrária extensa e eficiente. Poderíamos descrever a economia chinesa nesse momento como dual, composta por um vasto território agrícola com poucas cidades

\footnotetext{
${ }^{2}$ A despeito de ter terminado oficialmente em 1969, podemos dizer que seus desencadeamentos continuaram até a morte de Mao Tsé-Tung, em 1976 (Medeiros, 2008).
} 
"industriais" ao seu redor ${ }^{3}$. A economia era amplamente dependente da agricultura, com $80 \%$ da população no campo e mais de $70 \%$ do $\mathrm{PIB}^{4}$ advindo do setor primário (Nabuco, 2009, p. 1; Yang e Fang, 2000, p. 38).

Nesse sentido, pode-se dizer que a criação das bases para o desenvolvimento industrial passava necessariamente pela tão esperada reforma agrária, uma vez que o setor primário tem um papel determinante nesse processo. Primeiramente, porque é necessário que o setor primário esteja preparado para suprir a indústria com matérias primas, bem como suprir os trabalhadores da cidade com alimentos. Adicionalmente, porque é por meio da apropriação da acumulação primitiva, possibilitada pelo aumento da produtividade do campo, que o governo chinês obtém os recursos (capital-dinheiro) necessários aos empreendimentos industriais. E, por fim, para que haja a criação da grande indústria é necessário que haja mercado para os bens por ela produzidos. Dessa forma, a ampliação do produto do campo e, consequentemente, da renda do trabalhador agrícola possibilita que haja demanda para os bens produzidos pela indústria nascente. É possível observar que a estratégia de industrialização estava intimamente ligada a uma reestruturação do setor primário.

Além disso, somadas à interdependência entre industrialização e transformações na estrutura agrícola, (1) a busca por uma sociedade mais igualitária e (2) a questão histórica da fome $\mathrm{f}^{5}$ no país tornavam latente a necessidade de se realizar uma ampla reforma agrária.

Essa foi uma das primeiras ações de Mao Tsé-Tung no poder. A dimensão dessa reforma foi realmente extensiva: estima-se que 47 milhões de hectares aproximadamente - quase a metade das terras cultivadas - tenham sido divididos entre $300 \mathrm{mi}$ lhões de camponeses pobres, sendo dois terços de hectare por família. A mudança na estrutura foi notória: cerca de 40 milhões de camponeses com uma propriedade relativamente superior à média tiveram suas propriedades reduzidas; 70 milhões de camponeses simplesmente mantiveram sua propriedade; e 300 milhões de camponeses pobres conquistaram sua propriedade. A reforma agrária avançou além da distribuição de terras aos camponeses, pois uma série de fazendas e granjas estatais

\footnotetext{
${ }^{3}$ Estima-se que $70 \%$ de todo o produto industrial estavam na costa, onde apenas oito cidades representavam 55\% deste total, quais sejam: Pequim, Taianjin, Shanghai, Shenyang, Anshan, Benxi, Dalian, Fushun (Yang, 1990, p. 234).

${ }^{4}$ Dado de 1952 (Maddison e Wu, 2007, p. 14); a evolução dos componentes do PIB pode ser encontrada na Tabela 3.

${ }^{5}$ A China historicamente sofreu de surtos de fome. É importante destacar que esse não era apenas um problema distributivo de alimentos, mas uma questão de verdadeira carência destes. Possuindo apenas 7\% da área agriculturável do mundo e $23 \%$ da população mundial, o fantasma da fome sempre assombrou o povo chinês, que o vivenciou em diversos momentos de sua história (Fairbank e Goldman, 2006, p. 5).
} 
foi organizada, possibilitando que muitos passassem a trabalhadores assalariados ${ }^{6}$ (Pagotto, 2006, p. 2).

Como a economia no período se ancorava na agricultura, uma reforma desse porte significava em última instância estimular a economia, garantindo renda à população, plantando as sementes para o desenvolvimento industrial que viria nos períodos subsequentes ${ }^{7}$.

Nos três primeiros anos após a revolução, o clima favorável e a reestruturação trouxeram um grande aumento da produção. Após 1952 houve novas reestruturações, nas quais os camponeses foram organizados em cooperativas para que houvesse aumento da produção com ganhos de escala. Aos poucos, os agricultores foram obrigados a entregar suas produções ao governo por meio das agências estatais. Logo as trocas efetuadas por agentes privados foram extintas e o governo passou a ser o único distribuidor ${ }^{8}$. Como mostra Paggoto:

A gestão das cooperativas de tipo inferior era realizada por meio de uma direção e as famílias trabalham como equipes. As glebas foram unificadas, sendo trabalhadas como uma única unidade produtiva. O resultado da produção continuava a pertencer ao usufruto de cada família, mas calculado por um sistema de "pontos-trabalho". Esse sistema surge como uma forma de remunerar de um modo mais justo o trabalho agrícola. $\mathrm{Na}$ época dos grupos de ajuda mútua, a remuneração do trabalho era feita pelo resultado de uma jornada (ou meia jornada) de trabalho, sem levar em conta a qualidade ou a quantidade do trabalho realizado ${ }^{9}$. Depois da formação das cooperativas, esse sistema mostrou-se insuficiente, na medida em que se buscava uma maneira de remunerar o trabalho por meio de um sistema em que pudesse aplicar o princípio de "a cada um segundo o seu trabalho". (Marchisio, 1966 apud Paggoto, 2006, p. 6)

Além da reforma no campo, assistiu-se a uma reestruturação nas cidades. O Partido Comunista Chinês (PCC) mostrou-se capaz de auto reformar a estrutura montada no império e, principalmente, eliminar as camadas burguesas que se beneficiavam e se apro-

\footnotetext{
${ }^{6}$ Para impedir uma forte migração para as cidades, dificultando o planejamento da industrialização, foi criado o hukou, sistema que vincula cada indivíduo ao seu local de residência. Assim, um indivíduo que estivesse fora de seu hukou, não teria acesso aos sistemas hospitalar, educacional, etc. Outro fator importante é que os indivíduos ficaram proibidos de trabalhar permanentemente fora de seu hukou (Oliveira, 2007, p. 2).

${ }^{7}$ Como o Estado organizava a produção e se comprometia a comprar a produção dos agricultores, estes ampliaram suas culturas. A ampliação da produção agrícola garantia o fornecimento de matérias primas para a indústria, ao mesmo tempo em que gerava renda para os camponeses. Com renda, a população do campo tornava-se mercado consumidor para os produtos industrializados, garantindo, assim, minimamente alguns dos pré-requisitos para a formação da grande indústria.

${ }^{8}$ Sabemos que a reestruturação desse sistema pós-1978 foi capaz de trazer grande aumento de produtividade e iniciar um processo de modernização da indústria; no entanto, devemos ter em mente que a estratégia adotada por Mao Tsé-Tung nesse período foi bem sucedida no sentido de gerar uma sociedade igualitária, além de dar poder de coordenação ao governo central por meio do controle da produção.

${ }^{9}$ Ao reestruturar a agricultura de forma a alterar o modo de remuneração, Deng Xiaoping logrou êxito em ampliar fortemente a produtividade agrícola nos primeiros anos pós-1978 (nota inserida pelos autores).
} 
priavam do governo. Com isso, iniciou-se uma série de reformas, em que as empresas privadas existentes eram obrigadas a tomar empréstimos com fundos públicos e, dessa forma, trabalhar sob contrato com órgãos fiscais, dos quais recebiam, além de crédito, matérias primas. Em meio a esse processo, o Estado forçou uma série de fusões entre as estatais e estas empresas, que passaram a ser propriedade do governo (Paggoto, 2006, p. 4).

Assim, poucos anos após a revolução, o Estado já possuía uma rede de empresas estatais, controlava a produção e o fornecimento de bens agrícolas. Podemos dizer que essas reformas deram ao PCC as ferramentas iniciais para se levar a cabo uma estratégia industrializante com forte controle e planejamento estatal. Em um sentido mais amplo, observa-se que o caráter revolucionário imposto por Mao durante todo seu governo, com reformas impactantes e mobilização popular, foi fundamental e tinha o objetivo de quebrar o imobilismo tradicional, conduzindo as mudanças necessárias à modernização chinesa.

A ruptura do imobilismo aliada a mecanismos de incentivo ao aumento da produção e produtividade - como a reforma agrária que deu terra aos camponeses, aliada à remuneração do trabalho de acordo com o quantum produzido - são aspectos centrais para uma sociedade que pretende se industrializar. A paralisia propiciada por uma classe dominante que não deseja avançar com reforma econômicas estruturais dificulta e até certo ponto inviabiliza as mutações necessárias à constituição de uma sociedade industrial. Além disso, os mecanismos de incentivo ao aumento da produção são fundamentais para que se tenha dinamismo suficiente para criar uma indústria pesada.

\section{A FORMAÇÃO DE UMA INDÚSTRIA PESADA}

A criação de uma indústria pesada é condição básica para o desencadeamento de um processo mais amplo de industrialização. Com a formação desta asseguram-se os bens básicos para a formação das indústrias de bens de consumo. É somente após a formação da indústria de base que a industrialização ganha força e é capaz de avançar nos mais diversos setores com ganhos de eficiência e produtividade, que marcam o processo mais amplo de industrialização. Como mostra Oliveira, é na era Mao Tsé-Tung que esse processo ganha forma:

(...) E mesmo do ponto de vista econômico o passado pré-reformas na China deixou o legado representado pela montagem da indústria pesada no país, condição para a rápida expansão da produção de bens de consumo pós-reformas. (Oliveira, 2005, p. 5, grifo nosso)

O objetivo de acelerar o processo de industrialização chinesa é um aspecto marcante da estratégia de desenvolvimento do período, que optou por seguir os moldes soviéticos 
Tabela 1 - Valor bruto da produção, $1^{\circ}$ Plano Quinquenal, 1953-1957

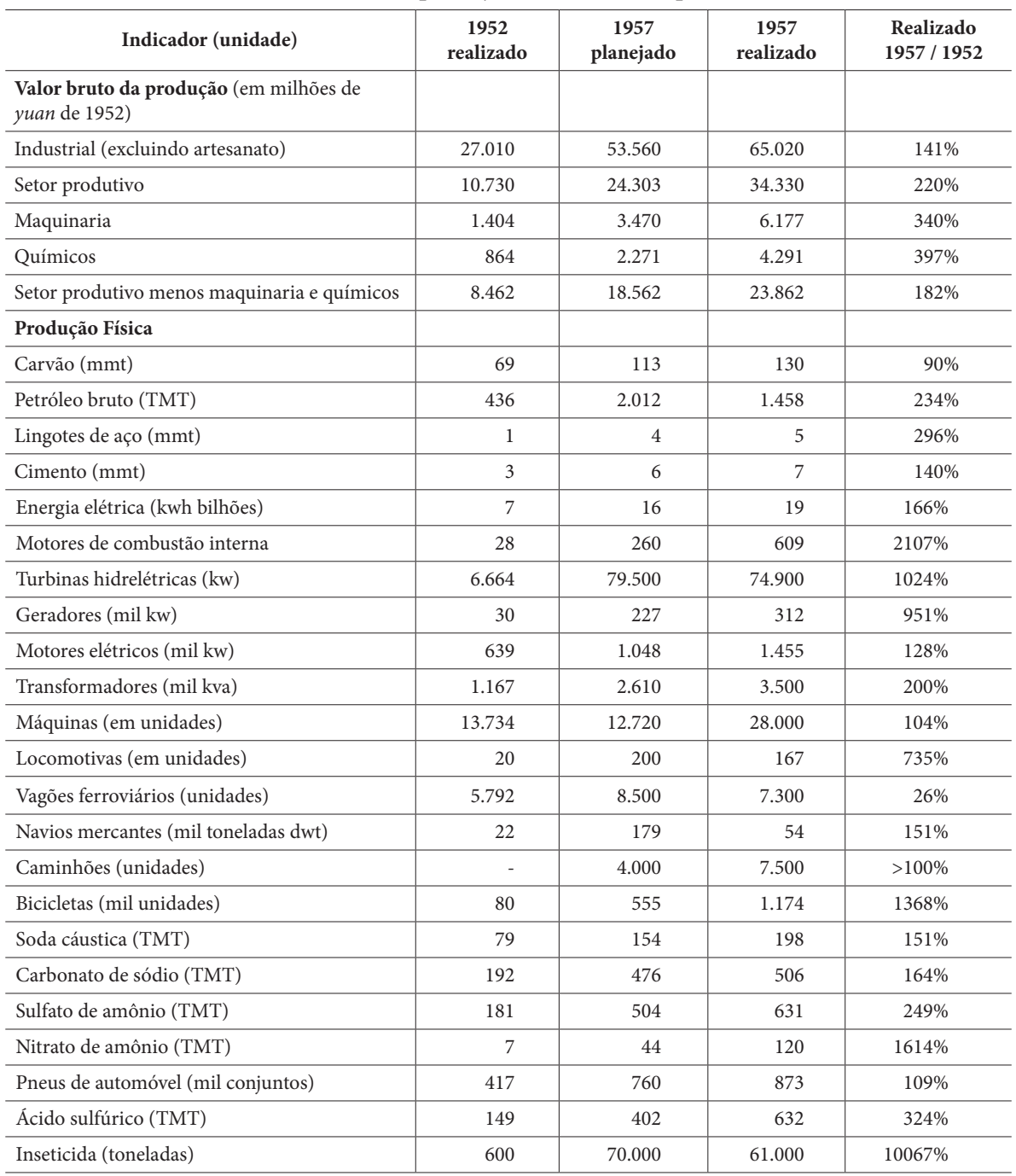

Fonte: Elaboração própria com base em dados de Spence (1990, p. 543).

pautados na estatização da indústria existente. O objetivo principal dessa ação foi centralmente planejar a economia de forma a garantir uma industrialização rápida e homogênea no território chinês ${ }^{10}$ (Gonçalves, 2006; Ruiz, 2006).

${ }^{10}$ Durante a era Mao Tsé-Tung, houve certa convergência na industrialização regional. A homogeneização era um caráter bastante presente na estratégia industrializante de Mao. Já no período seguinte as diferenças regionais cresceram e hoje representam um grande desafio aos governantes chineses (Ruiz, 2006). 
Já no primeiro plano quinquenal (1953-1957) proposto por Mao Tsé-Tung foi possível observar evolução nesse sentido. A Tabela 1 mostra o valor bruto da produção para esse período. Pode-se observar que o produto industrial registrou grande incremento: cresceu de 27 para 65 bilhões de yuan entre 1952 e 1957. Mesmo com uma base reduzida - apenas 1,4 bilhão yuan - o crescimento auferido pelo setor de maquinários no mesmo período também foi relevante, 340\%. Este setor é estratégico, uma vez que seu crescimento favorece os demais setores industriais, possibilitando a estes que nos próximos períodos possuam máquinas para incrementar suas próprias produções. Outro fator importante diz respeito à possibilidade de se desenvolver localmente uma indústria de base, minimizando a dependência das importações de máquinas e equipamentos.

No que diz respeito à produção física, é possível observar que houve um aumento em todos os itens que temos registro. É interessante notar como alguns desses componentes vão de encontro ao processo de industrialização chinesa. Itens estratégicos para a formação da indústria e o aumento da produção tiveram um forte crescimento, como máquinas (104\%), motores de combustão interna (2107\%), motores elétricos $(128 \%)$ e transformadores (200\%). Esses itens são a base da indústria e indicam, de certa forma, o empenho do país em se preparar para montar seu parque industrial. Outro ponto central na criação da grande indústria é a disponibilidade de energia, sem a qual não há produção. Assim, o crescimento expressivo auferido em setores como o de geradores (951\%), turbinas hidrelétricas (1024\%), energia elétrica (166\%) e petróleo (104\%), mostra que a indústria caminhava rumo ao aumento expressivo da produção. Cabe também destacar que a produção de importantes insumos industriais, como o aço e o cimento, foram fortemente ampliadas, respectivamente, em $296 \%$ e $234 \%$.

Outro ponto de destaque foi o aumento de itens relacionados ao transporte. Esses itens são especificamente importantes, pois, além de dinamizar a indústria, possibilitam $o$ atendimento a mercados mais distantes, ampliando assim a abrangência do mercado interno para os produtos industriais. Alguns itens de destaque foram os caminhões, que nunca haviam sido produzidos localmente e nesse período passaram a fazer parte do portfólio industrial do país; a produção de pneus mais que dobrou; e a produção de navios mercantes se ampliou em 109\%. Além desses itens, o número de locomotivas cresceu $735 \%$ e o de vagões ferroviários, $26 \%$. E em que pese o fato de estes não terem atingido a meta do plano quinquenal, favoreceram a reconstrução do transporte ferroviário, que havia sido devastado pelas guerras, possibilitando que em poucos anos fosse reparado e ampliado (Paggoto, 2006, p. 1).

Como já assinalado anteriormente, a produção industrial dependia fortemente da produção agrícola, tanto para suprir a cidade com matérias primas, quanto para que o 
campo tivesse renda para criar mercado para os produtos industriais. Assim, atrelado à estratégia de industrialização, o aumento da produção agrícola era fundamental e, dessa forma, houve um forte incremento de insumos agrícolas, como os inseticidas, cuja produção física foi aumentada em mais de 100 vezes. Pode-se dizer, portanto, que nesse período focou-se na criação das bases de uma industrialização mais sólida, sem deixar de incentivar também a principal geradora de renda no momento - a agricultura -, com criação/ampliação da indústria de insumos agrícolas, já que a formação da indústria dependia da agricultura (Spence, 1990, p. 547).

O governo não apenas coordenava/controlava o processo de industrialização, mas também investia. A Tabela 2 mostra a distribuição do capital fixo investido pelo Estado chinês no período de 1952 a 1957. Observa-se claramente que o governo ampliou seu foco na indústria, que passou a receber em 1957 mais da metade de todo o investimento fixo estatal.

Tabela 2 - Distribuição do investimento fixo estatal em 1952, 1955 e 1957

\begin{tabular}{l|c|c|c}
\hline \multicolumn{1}{c|}{ Setor } & $\mathbf{1 9 5 2}$ & $\mathbf{1 9 5 5}$ & $\mathbf{1 9 5 7}$ \\
\hline Indústria & $39 \%$ & $46 \%$ & $52 \%$ \\
\hline Construção & $2 \%$ & $4 \%$ & $3 \%$ \\
\hline Prospecção de recursos naturais & $2 \%$ & $3 \%$ & $2 \%$ \\
\hline Agricultura, silvicultura, gestão da água e meteorologia & $14 \%$ & $7 \%$ & $9 \%$ \\
\hline Transporte e comunicação & $18 \%$ & $19 \%$ & $15 \%$ \\
\hline Comércio & $3 \%$ & $4 \%$ & $3 \%$ \\
\hline Cultura, educação e pesquisa & $6 \%$ & $6 \%$ & $7 \%$ \\
\hline Saúde pública e bem-estar & $1 \%$ & $1 \%$ & $1 \%$ \\
\hline Serviços públicos urbanos & $4 \%$ & $2 \%$ & $3 \%$ \\
\hline Administração do governo & $0 \%$ & $2 \%$ & $1 \%$ \\
\hline Outros & $11 \%$ & $7 \%$ & $4 \%$ \\
\hline Total em \% & $\mathbf{1 0 0 \%}$ & $\mathbf{1 0 0} \%$ & $\mathbf{1 0 0 \%}$ \\
\hline Total (em milhões de yuan) & $\mathbf{4 . 3 6 0}$ & $\mathbf{9 . 3 0 0}$ & $\mathbf{1 3 . 8 3 0}$ \\
\hline
\end{tabular}

Fonte: Elaboração própria com base em dados de Spence (1990, p. 546).

Diante do crescimento vivenciado no primeiro plano quinquenal e da necessidade de manter um processo acelerado de crescimento com modernização industrial, Mao Tsé-Tung confiou ao "Grande Salto Adiante" a responsabilidade de manter as transformações necessárias ao desenvolvimento do país no período seguinte.

O plano representava a tentativa de realizar uma ampla transformação econômica e política de maneira acelerada. Na dimensão política, o plano foi marcado pela perseguição aos "direitistas" e pela tentativa de transformar a China em uma sociedade verdadeiramente comunista em poucos anos (Naughton, 2006, p. 69). Já na dimensão 
econômica, buscou-se aprofundar a coletivização do campo com a criação de comunas em todas as regiões do país, de forma a atingir a descentralização das atividades produtivas com a expansão acelerada de pequenas indústrias rurais. As comunas ficavam então responsáveis por organizar/expandir a produção, criar infraestrutura regional e até mesmo proteger o território por meio de milícias (Ruiz, 2006, p. 6-7). Adicionalmente, procurou-se, em emulação ao modelo soviético, transformar os investimentos em indústrias pesadas num dos principais agentes da transformação estrutural da economia chinesa.

As metas eram verdadeiramente ousadas e deveriam ser colocadas em prática pela própria população ${ }^{11}$. Esse processo se mostrou pouco exitoso na medida em que não era possível às comunas efetivamente expandir a produção e garantir o crescimento sem um mínimo de coordenação e centralização política e econômica. Como aponta Ruiz (2006):

(...) não obstante as escalas dos mercados regionais, a economia chinesa já estava estruturada em torno de um forte comércio inter-regional. Como a descentralização produtiva não foi acompanhada por nenhuma coordenação das diversas atividades produtivas, o sistema econômico entrou rapidamente em colapso. Os resultados dessas mudanças na organização da produção foram trágicos: o segundo plano quinquenal (1957-1962) não foi implementado, a produção agrícola de 195 milhões de toneladas de grãos em 1957 reduzira-se para menos de 150 milhões de toneladas em 1960. Alguns analistas reportam que de 10 a 30 milhões de pessoas morreram devido a desestruturação da produção agrícola e seus consequentes impactos na produção industrial (...). (Ruiz, op.cit., p. 7, grifo nosso)

Ainda que esse processo tenha permitido alguma descentralização da produção e das indústrias rurais, o período ficou marcado por uma queda acentuada da produção e, principalmente, pela fome generalizada. No entanto, cabe destacar que, mesmo sobredimensionados, os investimentos em indústrias pesadas e infraestrutura realizados no "Grande Salto Adiante" contribuíram para a expansão industrial no período imediatamente posterior. Adicionalmente, pode-se inferir

\footnotetext{
${ }^{11}$ Foge do escopo deste artigo analisar os determinantes políticos do projeto de Mao Tsé-Tung. No entanto, uma ressalva faz-se oportuna. Apesar de inicialmente este projeto aparentar ser extremamente irracional, Oliveira (2005, p. 4) chama a atenção para o fato de que “(...) se atentarmos não somente para os alvos perseguidos nesse movimento, ou seja, a luta contra as quatro velharias: a cultura, o pensamento, os hábitos e os costumes; mas também para o fosso existente tradicionalmente na China entre as camadas cultas e o povo em geral, poderemos compreender a lógica que governava esses movimentos. O conhecimento do passado da China imperial, sua sociedade petrificada no dizer de Weber, seu governo exercido por mandarins confucianos, que rejeitavam e bloqueavam mudanças, pois estas ameaçavam a harmonia do mundo; e a percepção de que os valores tradicionais ainda impregnavam os comportamentos dos agentes sociais, com esse quadro, a dinâmica das lutas internas recobra seu sentido.”.
} 
que a iniciativa de planejamento econômico estatal adotada no período - ainda que bastante problemática - tenha contribuído em alguma medida para consolidar uma característica inerente à dinâmica de acumulação chinesa: o controle estatal do investimento.

Assim, a despeito do mau desempenho econômico vivenciado nos anos pós "Grande Salto Adiante”, quando se analisa a era Mao Tsé-Tung como um todo é possível observar um período de crescimento acelerado com fortes transformações industriais. $\mathrm{O}$ Gráfico 1 mostra a evolução do PIB nesse período, em milhões de yuan. Observa-se que, apesar de se reduzir em períodos específicos - logo após o "Grande Salto Adiante" e início da revolução cultural -, o PIB chinês mantém uma trajetória ascendente, com crescimento real médio superior a $4 \%$ a.a..

Gráfico 1 - PIB (em milhões de yuan de 1987)

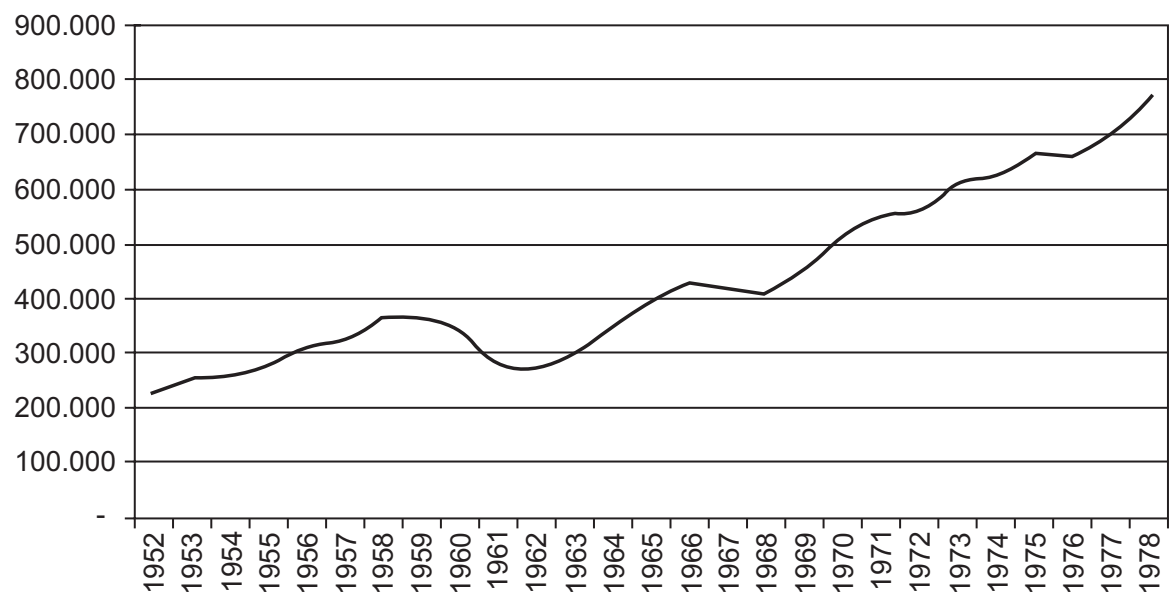

Fonte: Elaboração própria com base em dados de Maddison e Wu (2007, p. 159).

Além do crescimento do PIB auferido na era Mao Tsé-Tung, assistiu-se também a uma transformação qualitativa no sistema produtivo chinês, com uma crescente participação da indústria no PIB, em detrimento de uma menor participação da agricultura. Pode-se observar na Tabela 3 que em 1952 a participação da agricultura era superior a $70 \%$ do PIB, mostrando que a economia era primordialmente agrária e que a indústria era praticamente inexistente (sua participação não chegava a $8 \%$ ). Com as reformas de Mao Tsé-Tung e o foco na indústria de base, esta passou a ter uma participação crescente no PIB. Em 1978, 36\% do PIB chinês já eram formados pela indústria e 37\%, pela agricultura. Em que pese o ainda relevante tamanho do setor primário na composição 


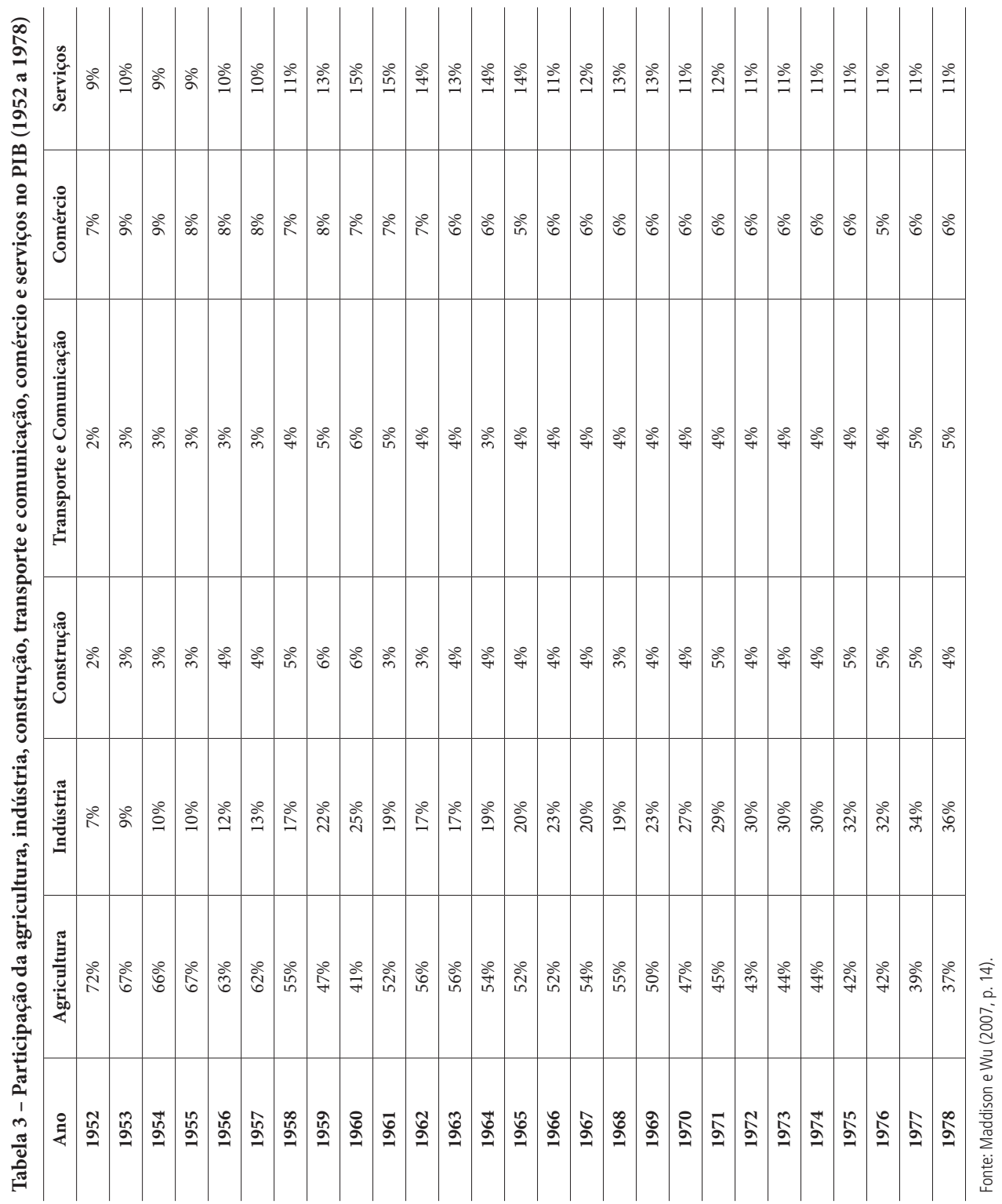


do PIB chinês, não se pode deixar de reconhecer que a indústria já havia sido montada e era igualmente importante para o país ${ }^{12}$.

Dessa forma, podemos concluir que os primeiros passos rumo à industrialização chinesa já haviam sido dados na era Mao Tsé-Tung. Em 1978, a participação da indústria já era bastante significativa $(36 \%)^{13}$, mostrando que o esforço industrializante empreendido por Mao possibilitou a criação de um parque industrial robusto, ainda que atrasado. Esse parque foi fundamental para que Deng Xiaoping pudesse empreender seu plano bem sucedido de modernização. Nas palavras de Medeiros:

A China apresentava uma estrutura semi-industrializada - em que pese a presença de um importante setor de bens de capital - com a maioria da população ocupada na agricultura, residindo em vilas e municípios. Também em regime de pleno emprego, possuía reduzida participação de trabalhadores qualificados na população economicamente ativa (PEA), baixa diversificação nos padrões de consumo e grande nivelamento social. Do ponto de vista do comércio exterior, vivia de forma semiautárquica. (Medeiros, 2008, p. 8, grifos nossos)

Além da indústria de base, dois outros fatores foram centrais para viabilizar o salto modernizante empreendido por Deng Xiaoping: (1) ampliação da área irrigada com amplos investimentos em infraestrutura hidráulica e (2) criação/consolidação da indústria de insumos agrícolas.

\section{AUMENTO DA ÁREA IRRIGADA E CRIAÇÃO DE UMA INDÚSTRIA DE INSUMOS AGRÍCOLAS}

Muitos autores consideram que uma das principais reformas responsáveis pelo sucesso da industrialização chinesa pós-1978 foi a reforma agrária empreendida por Deng Xiaoping, a partir em $1979^{14}$. Além de estimular a produtividade, aumentar o produto e a renda dos trabalhadores, essa reforma foi fundamental para fomentar a produção

\footnotetext{
${ }^{12}$ Como se sabe, é bastante difícil encontrar estatísticas de períodos anteriores a 1978; os dados aqui apresentados foram calculados a partir dos valores apresentados por Maddison e Wu (2007, p. 14), que por sua vez coletaram estes dados do Historical National Accounts of the Peopleis Republic of China (National Bureau of Statistics of China,1997), fonte oficial do governo chinês. Infelizmente, os dados para o ano de 1978 divergem dos apresentados pela United Nations Conference on Trade and Development (UNCTAD) no Handbook of Statistics (UNCTAD, 2010) e dos apresentados no China Statistical Yearbook (National Bureau of Statistics of China, 2010) - também fonte oficial chinesa -, para os quais a participação do setor primário é de $28 \%$; do secundário, 48\%; e do terciário, 24\%. Infelizmente essas duas fontes não possuem dados anteriores a 1978. De qualquer forma, nas três fontes os dados indicam que a indústria em 1978 já possuía uma participação importante no produto chinês, convergindo para a tese de que o legado deixado por Mao Tsé-Tung colaborou para o rápido desenvolvimento do período posterior.

${ }^{13}$ Ou 48\% para UNCTAD (2010) e National Bureau of Statistics of China (2010).

${ }^{14}$ Ver Medeiros (1999), Oliveira (2005) e Leão (2010).
} 
industrial no período. Como mostra Oliveira, tal reforma somente foi possível devido à existência de condições mínimas de produção, quais sejam: uma indústria de insumos agrícolas desenvolvida e uma boa infraestrutura de irrigação.

Certos autores chamam a atenção para o fato de que, para esse sucesso foram também fundamentais tanto as grandes obras hidráulicas, construídas anteriormente, que aumentaram a área irrigada do país; assim como a implantação no país, antes das reformas, de grandes empresas industriais estatais produtoras de insumos modernos para a agricultura, as quais se mostraram capazes de atender à crescente demanda das unidades familiares camponesas. (Oliveira, 2005, p. 6)

A análise da Tabela 4 mostra que entre 1952 e 1978 houve forte formação/ampliação da indústria de insumos agrícolas. $\mathrm{O}$ aumento na produção de fertilizantes químicos foi surpreendente: passou de 39 mil para 8,69 milhões de toneladas entre 1952 e 1978; a ampliação na produção de fertilizantes nitrogenados também foi significativa: partiu de sete mil toneladas em 1952, para 257 mil toneladas em 1978; outro insumo muito importante para a ampliação da produtividade são os pesticidas, que praticamente inexistiam em 1952 - produziam-se apenas duas mil toneladas - mas atingiram a marca de 533 mil toneladas em 1978. A estruturação da indústria de insumos agrícolas foi fundamental para viabilizar a ampliação da produtividade do setor primário e possibilitar o salto industrializante.

Um dos principais fatores de sucesso das reformas iniciadas por Deng-Xiaoping foi sua ampla reforma agrária, capaz de dinamizar o campo e ampliar a produção. Dessa forma, a expansão da área irrigada na era Mao colaborou para o rápido crescimento agrícola nos primeiros anos pós-1978. Podemos observar que a área irrigada em 1952 era de aproximadamente 20 milhões de hectares; já em 1978, passava dos 44 milhões. Em paralelo a esse incremento houve também a ampliação na participação da irrigação mecânica e elétrica. Enquanto em 1952 menos de 2\% de toda a área irrigada eram feitos por bombas mecânicas ou elétricas, em 1978 mais da metade da área irrigada já possuía esse fator estratégico inserido. A não utilização de bombas para irrigação faz com que o esforço necessário para a irrigação seja alto e com baixa produtividade. Assim, com a modernização das técnicas, foi possível ampliar não só a área irrigada, mas, novamente, a produtividade.

A ampliação da indústria de insumos agrícolas, bem como o aumento da área irrigada, não aconteceu por acaso. Amplos investimentos estatais foram aplicados para que esses empreendimentos fossem formados. O gasto total com agricultura, que era de 0,9 bilhão de yuan em 1952, atingiu a marca de 15,1 bilhões ao final da era Mao, evidenciando o empenho governamental em desenvolver a agricultura - ainda a principal fonte de renda dos trabalhadores. Ainda em relação à Tabela 4, vale enfatizar que no início do primeiro plano quinquenal (1952) mais de 87\% de todo o emprego na China 
Tabela 4 - Indicadores selecionados (1952, 1965, 1978, 1992 e 2006)

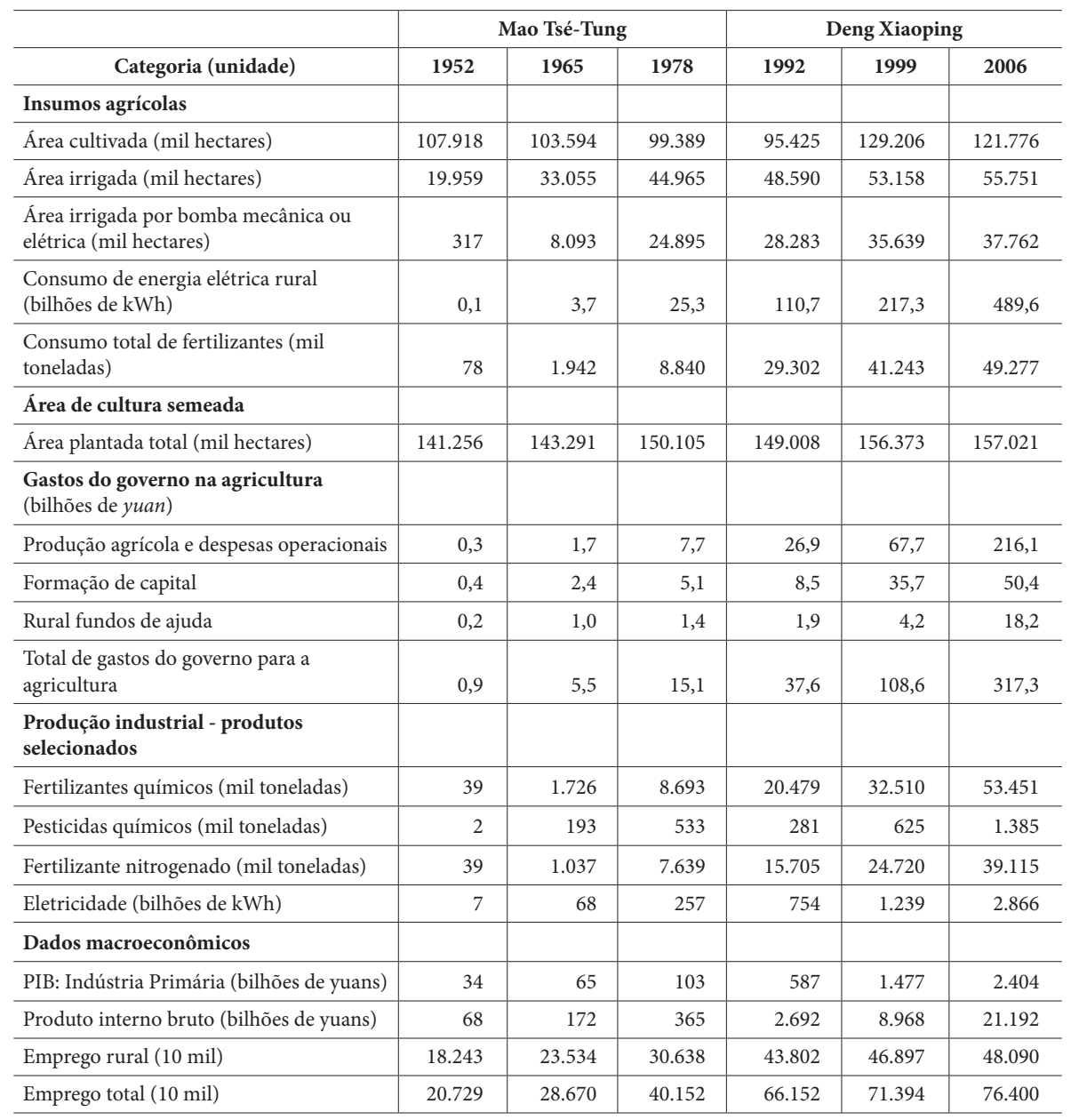

Fonte: Elaboração própria com base em dados de USDA (2011).

era rural, ao passo que ao final da Era Mao este era de 76\%. Ou seja, a despeito do sucesso em iniciar o processo de industrialização (principalmente a indústria de bens de capital), a China ainda possuía em sua estrutura social o setor primário como principal gerador de renda ao trabalhador. O que se observou foi um grande aumento no nível de emprego, com maior crescimento do industrial.

Reformas como essas são fundamentais para acelerar o processo de industrialização. Com a ampliação do setor primário, o campo é capaz de abastecer a indústria com matérias primas. Ao produzir e encontrar mercado para seus produtos (matérias primas e bens primários), o campo gera renda e se transforma em mercado para 
produtos industrializados. Ao encontrar mercado para seus produtos, o processo produtivo industrial é viabilizado e o ciclo de produção e ampliação da indústria, concretizada. Dessa forma, ao ampliar a área irrigada e ampliar a indústria de insumos agrícolas, o Estado estimula, em última instância, a formação da grande indústria na cidade.

Diante do exposto, defende-se a tese de que as bases para a industrialização foram criadas na era Mao Tsé-Tung com o apoio de reformas, como (1) a quebra do imobilismo tradicional, (2) a formação da indústria pesada e (3) o aumento da área irrigada e da produção de insumos agrícolas. Esses três fatores foram pré-condição para o sucesso das reformas econômicas de Deng Xiaoping.

\section{CONCLUSÃO}

Ao se analisar o processo de industrialização chinesa, usualmente parte-se da tomada de poder por Deng Xiaoping, em 1978. Foi argumentado neste artigo que o processo de modernização da indústria chinesa pós-1978 foi facilitado pelas reformas implementadas por Mao Tsé-Tung no período anterior (1949-1976). Compreender essas reformas significa, em última instância, antecipar o ponto de partida para o sucesso pós-1978.

A quebra do imobilismo político e social, espelhado na conduta revolucionária imposta por Mao Tsé-Tung durante todo o seu governo, buscava em última instância evitar a solidificação e a imobilização de uma nova estrutura de classes. Para que uma nação consiga avançar rumo à industrialização é necessário que reformas estruturais sejam realizadas, reformas estas que demandam uma alteração importante nos mecanismos de incentivo para acumulação, muitas vezes inviabilizada pelo imobilismo. A quebra do imobilismo na era Mao Tsé-Tung de certa forma garantiu a criação de uma sociedade mais igualitária, bem como um constante movimento rumo à industrialização. Este fator foi fundamental para viabilizar as mudanças sociais e econômicas necessárias à criação e ao fortalecimento da indústria de pesada -, bem como a incorporação do Estado nas diversas estruturas sociais e produtivas existentes. A existência dessa indústria pesada foi importante para viabilizar o processo de industrialização acelerado pós-1978.

Tanto a formação da indústria de insumos agrícolas, quanto a ampliação da área irrigada foram fundamentais para viabilizar o aumento da produtividade auferido pela reforma agrária implementada por Deng Xiaoping após sua chegada ao poder, em 1978. Essa reforma classificada como um dos pontos determinantes para o avanço da economia chinesa no período recente, conforme se mostrou neste artigo, foi amplamente beneficiada pelos avanços herdados da era Mao Tsé-Tung. 
Estas foram apenas algumas reformas realizadas no período compreendido entre 1949 e 1976 que influenciaram decisivamente o processo de transformação industrial acelerado do período subsequente. Obviamente, o legado deixado por Mao não se esgota nesses itens. Tampouco se pode afirmar que inexistiram incoerências em seu projeto de desenvolvimento. Tendo essas restrições em mente, buscou-se aqui resgatar algumas contribuições para este processo de industrialização que certamente é um dos mais bem sucedidos do último século.

\section{REFERÊNCIAS}

FAIRBANK, K. J.; GOLDMAN, M. China: a new history. London: The Belknap Press of Harvard University Press, 2006.

GONÇALVES, A. China's swing from a planned soviet-type economy to an ingenious socialist market economy: an account of 50 years. Working Papers Series, Social Sciences Research Network, 2006. Disponível em: <http://ssrn.com/abstract=949371 > ou <http://dx.doi. org/10.2139/ssrn.949371>. Acesso em: 01 ago. 2012.

LEÃO, R. P. F. O padrão de acumulação e o desenvolvimento econômico da China nas últimas três décadas: uma interpretação. 2010. 192 f. Dissertação de Mestrado, Pós-Graduação em Economia, Instituto de Economia da Unicamp, Universidade Estadual de Campinas, Campinas, 2010.

MADDISON, A.; WU, H. X. China's economic performance: how fast has GDP grown; how big is it compared with the USA? Papers, Center for International Comparisons at the University of Pennsylvania, 2007. Disponível em: <http://pwt.econ.upenn.edu/papers/Maddison-Wu\%20 \%28Harry\%27s\%20draft\%20version\%2029\%20Jan\%2007\%29.pdf>. Acesso em: 22 ago.2011.

MARCHISIO, H. Los sistemas de remuneración en las comunas populares. In: BETTELHEIM, C. et al. La construcción del socialismo en China. México: Ediciones Era, 1966. p. 78.

MEDEIROS, C. A. Economia política do desenvolvimento recente da China. Revista de Economia Política, v. 19, n. 3, 1999.

MEDEIROS, C. A. A economia política da transição na China e o colapso da União Soviética. 2008. mimeo. Disponível em: <http://www.ie.ufrj.br/datacenterie/pdfs/seminarios/pesquisa/ texto0605.pdf>. Acesso em: 23 set. 2011.

NABUCO, P. Do grande salto à “desmaoização": 20 anos de história chinesa. In: ENCONTRO NACIONAL DE ECONOMIA POLÍTICA, 14, 2009, São Paulo. Anais eletrônicos. São Paulo: Sociedade Brasileira de Economia Política, 2009. Disponível em: <http://sep.org.br/ artigo/1795_b201373ec82b28980a042b0984e40262.pdf>. Acesso em: 25 fev. 2011.

NATIONAL BUREAU OF STATISTICS OF CHINA. China Statistical Yearbook. Pequim: China Statistics Press, National Bureau of Statistics, 2010. Disponível em: <http://www.stats.gov. cn/english/statisticaldata/yearlydata/>. Acesso em: 19 maio 2011.

NATIONAL BUREAU OF STATISTICS OF CHINA. Historical National Accounts of the Peopleís Republic of China. Pequim: China Statistics Press, National Bureau of Statistics, 1997. 
NAUGHTON, B. The Chinese economy: transitions and growth. London: The MIT Press, 2006.

OLIVEIRA, A. P. A China em busca da terceira reforma agrária. São Paulo: IEA/USP, 2007. Disponível em: <http://www.iea.usp.br/artigos/portodeoliveirachina.pdf>. Acesso em: 10 mar. 2011.

OLIVEIRA, C. B. A. Reformas econômicas na China. Economia Política Internacional: análise estratégica, Campinas, n. 5, abr./jun., p. 3-8, 2005.

PAGOTTO, C. Apontamentos acerca das principais formas de cooperação na China entre 1950 e 1966. Novos Rumos, n. 46, 2006.

RUIZ, R. Polarizações e desigualdades: desenvolvimento regional na China (1949-2000). Belo Horizonte: UFMG/Centro de Desenvolvimento e Planejamento Regional, 2006.

SPENCE, J. D. The search for modern China. New York: Norton \& Company, 1990.

UNITED NATIONS CONFERENCE ON TRADE AND DEVELOPMENT (UNCTAD). Handbook of statistics 2010. New York and Geneve: United Nations, 2010. Disponível em: <http:// archive.unctad.org/en/docs/tdstat35_en.pdf>. Acesso em: 15 fev. 2011.

UNITED STATES DEPARTMENT OF AGRICULTURE (USDA). National data results. 2011. Disponível em: <http://www.ers.usda.gov/data-products/china-agricultural-and-economicdata.aspx>. Acesso em: 15 fev. 2011.

UNIVERSIDADE ESTADUAL DE CAMPINAS (UNICAMP). Embaixador Amaury Oliveira faz a palestra inaugural do Grupo de Estudos Brasil-China. Campinas, 12 ago. 2011. Disponível em: <http://www.unicamp.br/unicamp/divulgacao/2011/08/12/embaixador-amaury-oliveirafaz-a-palestra-inaugural-do-grupo-de-estudos-brasil>. Acesso em: 23 nov. 2011.

YANG, D. Patterns of China's regional development strategy. The China Quaterly, n. 122, jun., p. 230-257, 1990. Disponível em: <http://daliyang.com/files/Patterns_of_China_s_Regional_Development_Strategy.pdf>. Acesso em: 20 ago. 2012.

YANG, D. T.; FANG, C. The political economy of China's rural-urban divide. SCID Working Paper, Stanford University/Center for Research on Economic Development and Policy Reform, n. 62, Aug., 2000. Disponível em: <http://siepr.stanford.edu/publicationsprofile/1517>. Acesso em 20 ago. 2012. 